J. Dairy Sci. 97:5371-5382

http://dx.doi.org/10.3168/jds.2014-8144

(C) American Dairy Science Association ${ }^{\circledR}, 2014$.

\title{
Interactions between acidified dispersions of milk proteins and dextran or dextran sulfate
}

\author{
U. Pachekrepapol, ${ }^{*}$ D. S. Horne, $\dagger$ and J. A. Lucey ${ }^{1}$ \\ ${ }^{*}$ Department of Food Science, and \\ †Wisconsin Center for Dairy Research, University of Wisconsin-Madison, 1605 Linden Drive, Madison 53706
}

\begin{abstract}
Polysaccharides are often used to stabilize cultured milk products, although the nature of these interactions is not entirely clear. The objective of this study was to investigate phase behavior of milk protein dispersions with added dextran (DX; molecular weight $=2 \times 10^{6}$ Da) or dextran sulfate (DS; molecular weight $=1.4 \times$ $\left.10^{6} \mathrm{Da}\right)$ as examples of uncharged and charged polysaccharides, respectively. Reconstituted skim milk (5-20\% milk solids, wt/wt) was acidified to $\mathrm{pH} 4.4,4.6,4.8$, or 4.9 at approximately $0^{\circ} \mathrm{C}$ (to inhibit gelation) by addition of $3 \mathrm{~N} \mathrm{HCl}$. Dextran or DS was added to acidified milk samples to give concentrations of 0 to $2 \%$ (wt/ wt) and 0 to $1 \%$ (wt/wt) polysaccharide, respectively. Milk samples were observed for possible phase separation after storage at $0^{\circ} \mathrm{C}$ for 1 and $24 \mathrm{~h}$. Possible gelation of these systems was determined by using dynamic oscillatory rheology. The type of interactions between caseins and DX or DS was probed by determining the total carbohydrate analysis of supernatants from phase-separated samples. At 5.0 to $7.5 \%$ milk solids, phase separation of milk samples occurred after $24 \mathrm{~h}$ even without DX or DS addition, due to destabilization of caseins in these acidic conditions, and a stabilizing effect was observed when 0.7 or $1.0 \%$ DS was added. At higher milk solids content, phase separation was not observed without DX or DS addition. Similar results were observed at all $\mathrm{pH}$ levels. Gelation occurred in samples containing high milk solids $(\geq 10 \%)$ with the addition of 1.0 to $2.0 \%$ DX or 0.4 to $1.0 \%$ DS. Based on carbohydrate analysis of supernatants, we believe that DX interacted with milk proteins through a type of depletion flocculation mechanism, whereas DS appeared to interact via electrostatic-type interactions with milk proteins. This study helps to explain how uncharged and charged stabilizers influence the texture of cultured dairy products.
\end{abstract}

Received March 17, 2014.

Accepted June 8, 2014.

${ }^{1}$ Corresponding author: jlucey@cdr.wisc.edu
Key words: dextran, depletion flocculation, cultured dairy product

\section{INTRODUCTION}

Proteins and polysaccharides are 2 major components in food systems and contribute to formation of structure, texture, and stability of foods (Tolstoguzov, 1991; Doublier et al., 2000; Maroziene and de Kruif, 2000; Corredig et al., 2011). Polysaccharides used as stabilizers in production of fermented dairy products include starch and pectin. Some lactic acid bacteria that are used as yogurt starter cultures can produce exopolysaccharides (EPS), which can increase viscosity of stirred yogurt and decrease whey separation (Ruas-Madiedo et al., 2002). These EPS can be both uncharged and negatively charged (Girard and Schaffer-Lequart, 2008).

In mixtures of proteins and polysaccharides, the interactions between these 2 biopolymers can be segregative or associative (Tolstoguzov, 1991; Doublier et al., 2000; de Kruif and Tuinier, 2001). Segregative interactions result from thermodynamic incompatibility, which occurs when solvent-biopolymer interactions are favored over biopolymer-biopolymer interactions, whereas associative interactions are observed when interactions between 2 biopolymers are favored (Doublier et al., 2000).

Thermodynamic incompatibility between proteins and polysaccharides can induce phase separation due to depletion flocculation mechanisms (Doublier et al., 2000). A depleted layer of solvent (e.g., water) around protein particles is formed due to a loss of conformational entropy of polymers near an interface (Tuinier et al., 2003). As a consequence, osmotic potential difference causes the movement of solvent molecules from the depleted layer into the bulk. Protein particles then attract one another to reduce the volume of the depleted layer, which leads to a separation of the mixture into 2-phase system: a protein-rich phase and a polysaccharide-rich phase (McClements, 2000; Corredig et al., 2011).

In associative mixed-biopolymer systems, electrostatic interactions between oppositely charged proteins 
and polysaccharides are primary interactions; associative phase separation results from precipitation/sedimentation or bridging of proteins and polysaccharides (Doublier et al., 2000). During fermentation of milk, as the $\mathrm{pH}$ decreases from around $\mathrm{pH} 6.8$ to 4.4, the carboxyl groups of caseins become protonated and induce attractive interactions between caseins and negatively charged polysaccharides (Girard and Schaffer-Lequart, 2008). Therefore, in cultured products, the types of interactions between caseins and polysaccharides depend on conditions such as the $\mathrm{pH}$ value of milk (Everett and McLeod, 2005).

Phase diagrams between mixtures of milk proteins and several polysaccharides [e.g., amylopectin and dextran (DX)] have been developed for neutral $\mathrm{pH}$ conditions (Grinberg and Tolstoguzov, 1997), but only a few studies have been done in acidic conditions [e.g., phase behavior of casein micelles and high-methoxyl, low-methoxyl, and low-methoxyl amidated pectins in natural ( $\mathrm{pH}$ 6.7) and acidic conditions ( $\mathrm{pH} 5.3$ ); Maroziene and de Kruif, 2000]. They found that at $\mathrm{pH} 6.7$, phase separation occurred between caseins and $0.2 \%$ high-methoxyl and low-methoxyl amidated pectins and $0.1 \%$ low-methoxyl pectins (Maroziene and de Kruif, 2000). At $\mathrm{pH} 5.3$, all types of pectin adsorbed onto casein micelles and, upon increasing the concentration of pectin, casein micelles were fully coated by pectin molecules. However, phase behavior between milk proteins and polysaccharides in more acidic $\mathrm{pH}(\mathrm{pH}$ level $<5.0$; i.e., in fermented dairy products) has not been extensively investigated. Gelation of caseins at these acidic $\mathrm{pH}$ values presents a significant challenge, obscuring the effects of incompatibility or other ongoing interactions with polysaccharides.

This study aims to understand the effect of addition of uncharged and negatively charged polysaccharides on acidified milk with different solids content at various $\mathrm{pH}$ levels. We focused on aggregation of caseins, as milk solids content varied from 5 to $20 \%$ (wt/wt). Dextran was used in the study because it is a homoexopolysaccharide produced from Leuconostoc mesenteroides that can be obtained with known molar masses. Dextran is composed of glucose subunits, which are linked by $\alpha(1 \rightarrow 6)$ linkages on its main chain and $\alpha(1 \rightarrow 3)$ linkages on its side chain. Dextran sulfate (DS) is a derivative of DX with added sulfate groups $\left(\mathrm{SO}_{3}{ }^{-}\right)$, giving negative charges to the polysaccharide molecules.

To study these protein-polysaccharide interactions at acidic conditions, we used aspects of the cold milk acidification method developed by Roefs (1986). This allowed us to acidify milk and inhibit gelation due to the very low temperature. Polysaccharides could then be added to the mixtures to investigate the stability or instability of the acidified system.

\section{MATERIALS AND METHODS}

\section{Preparation of Reconstituted Skim Milk Stock Solution}

Low-heat nonfat dry milk was obtained from DairyAmerica Inc. (Fresno, CA) with a whey protein nitrogen index of $7.94 \mathrm{mg}$ of undenatured whey protein $/ \mathrm{g}$ of powder (Bradley et al., 1992). Reconstituted skim milk stock solution was prepared at a total milk solids content of $25 \%$ (wt/wt). The solution was stirred at approximately $25^{\circ} \mathrm{C}$ using a magnetic stirring unit overnight $(16-20 \mathrm{~h})$ before use. To prevent bacterial growth, $100 \mathrm{mg} / \mathrm{kg}$ of thimerosal $\left(\mathrm{C}_{2} \mathrm{H}_{5} \mathrm{HgSC}_{6} \mathrm{H}_{4} \mathrm{COO}-\right.$ $\mathrm{Na}$; Sigma-Aldrich, St. Louis, MO) was added as a preservative.

\section{Preparation of DX and DS Solutions}

Dextran (Sigma-Aldrich) with a molar mass of approximately $2 \times 10^{6}$ Da from Leuconostoc mesenteroides and DS (MP Biomedicals LLC, Solon, $\mathrm{OH}$ ) with a molar mass of approximately $1.4 \times 10^{6} \mathrm{Da}$ and a charge density of 1.9 sulfate groups/glucosyl residue were prepared by dispersing them in deionized water to make $10 \%$ (wt/wt) stock solutions. Thimerosal (100 mg/kg) was added to prevent bacterial growth. The solutions were stirred for $3 \mathrm{~h}$ at approximately $25^{\circ} \mathrm{C}$, and heated in a water bath at $85^{\circ} \mathrm{C}$ for $5 \mathrm{~min}$. These solutions were stored in an ice water bath before adding to milk.

\section{Preparation of Milk—DX or DS Dispersions}

Reconstituted skim milk stock solution was cooled in an iced water bath to approximately $0^{\circ} \mathrm{C}$ for $30 \mathrm{~min}$ before use. The skim milk was diluted by adding deionized water and mixing with $10 \%$ DX or DS solution to have a milk solids content of 5.0, 7.5, 10.0, 12.5, 15.0, 17.5 , or $20.0 \%$ (wt/wt), and DX concentrations of 0.5 , $1.0,1.5$, or $2.0 \%$ (wt/wt), or DS concentrations of 0.1 , $0.4,0.7$, or $1.0 \%$ (wt/wt).

To prepare the dispersions using the method developed by Roefs (1986), diluted milks were cooled to approximately $0^{\circ} \mathrm{C}$ to inhibit gelation and then slowly acidified to $\mathrm{pH} 4.4,4.6,4.8$ or 4.9 by adding $3 \mathrm{~N} \mathrm{HCl}$. The acid was added in $100-\mu \mathrm{L}$ increments with 1-min intervals. The $\mathrm{pH}$ of milk was measured by a $\mathrm{pH}$ meter (Accumet Basic AB 15plus; Fisher Scientific, Pittsburgh, PA). When the diluted milk samples reached the required $\mathrm{pH}$ levels, DX or DS solution was immediately added to milk to reach the required concentrations. After adding DX or DS solution, the $\mathrm{pH}$ of samples could slightly increase, and additional $\mathrm{HCl}$ was added to the samples. 


\section{Observation of Possible Phase Separation}

Approximately $10 \mathrm{~mL}$ of dispersions of acidified milk and polysaccharides were transferred to a $15-\mathrm{mL}$ conical plastic centrifuge tube (SpinMax $15 \mathrm{~mL}$; Crystalgen Inc., Commack, NY). Samples were stored at approximately $0^{\circ} \mathrm{C}$ in a refrigerated incubator (Precision model 815; Thermo Scientific, Waltham, MA) and visually observed for possible phase separation after 1 and $24 \mathrm{~h}$. Each sample was done in duplicate.

\section{Evaluation of the Interaction Mechanism Between Caseins and Polysaccharides}

The supernatant of phase-separated samples (without centrifugation) was analyzed for total carbohydrate content using the phenol-sulfuric acid method (DuBois et al., 1956). The supernatant was diluted and $2 \mathrm{~mL}$ of diluted supernatant were mixed with $50 \mu \mathrm{L}$ of $80 \%$ phenol. Five milliliters of concentrated sulfuric acid was added. The mixtures were shaken and allowed to stand for $15 \mathrm{~min}$ at temperature between 25 and $30^{\circ} \mathrm{C}$. The absorbance was measured at $490 \mathrm{~nm}$. Total carbohydrate content was expressed as glucose equivalents using a standard curve with glucose.

The results of the carbohydrate testing of the supernatant were used to understand possible interactions between caseins and polysaccharides as follows: for samples with the same milk solids content, if the total carbohydrate in supernatant remained constant as the added DX concentration was increased from 0 to $2.0 \%$ (or as the DS concentration was increased from 0 to $1.0 \%$ ), we assumed that phase separation resulted from associative interaction, in which the caseins and polysaccharides formed complexes and aggregated; thus, the carbohydrate concentration in the supernatant would not increase with increasing levels of DX or DS. On the other hand, if total carbohydrate concentration in the supernatant increased as DX or DS concentrations were increased, this would indicate phase separation, due to depletion flocculation.

\section{Microstructure of the Dispersions}

Microstructure of dispersions was studied using a fluorescent microscope (Axioskop 2 plus; Carl Zeiss Microscopy GmbH, Göttingen, Germany). Acridine orange (Sigma-Aldrich) was used as the fluorescent protein stain. Acridine orange $(300 \mu \mathrm{L}$ of $0.2 \%$ dissolved in deionized water) was added to $50 \mathrm{~mL}$ of cold acidified milk samples. One drop of the mixture was transferred to a microscope slide with concavity; the slide was stored at approximately $0^{\circ} \mathrm{C}$. Microstructure was observed at initial time after DX or DS addition $\left(\mathrm{T}_{0}\right)$ and after $24 \mathrm{~h}$ at approximately $0^{\circ} \mathrm{C}$. An excitation wavelength of $450 \mathrm{~nm}$ and an emission wavelength of $515 \mathrm{~nm}$ were used. To prevent temperature increase under the microscope, the focus of the microscope was set up using a model slide. The samples were observed and the micrographs were taken within 5 to $6 \mathrm{~s}$.

\section{Effect of DX or DS on Gelation of the Dispersions}

The effect of addition of DX or DS on possible gelation of the samples was studied using a rheometer (Paar Physica MCR301; Anton Paar USA Inc., Ashland, VA). The nondestructive rheological properties were determined by dynamic oscillatory frequency sweep test where frequency was varied from 0.001 to $1 \mathrm{~Hz}$, and the applied strain was $0.1 \%$, which was in the linear viscoelastic region. The multiwave function was used to reduce the testing time to $30 \mathrm{~min}$, and the resulting strain amplitude was 5.783. The cup and bob measuring geometry (CC27-SN23928), consisting of 2 coaxial cylinders (with diameters of 26.7 and 28.9 $\mathrm{mm}$ ) was used. Seventeen millimeters of samples were transferred to the rheometer at $\sim 0^{\circ} \mathrm{C}$ and samples were tested at that temperature. Gelation was defined as having occurred if the phase angle was $<45^{\circ}$. Storage modulus $\left(\mathbf{G}^{\prime}\right)$ values were also recorded.

\section{Viscosity of DX and DS solutions}

The effects of increased DX and DS concentrations on the viscosity of the milk samples were studied. The viscosity of DX and DS solutions (in absence of milk) at approximately $0^{\circ} \mathrm{C}$ was measured using the Paar Physica rheometer. Applied shear rate was logarithmically increased from 0.1 to $500 \mathrm{~s}^{-1}$. The double-gap measuring geometry (DG26.7; Anton Paar USA Inc.), consisting of 2 coaxial cylinders (with diameters of 26.7 and $23.8 \mathrm{~mm}$ ) was used.

\section{Statistical Analysis}

Total carbohydrate analysis of supernatants was repeated at least 3 times. An ANOVA was carried out using SigmaPlot 11.0 (Systat Software Inc., San Jose, $\mathrm{CA}$ ). The level of significant difference was determined at $P<0.05$. The differences between means were analyzed using the Fisher least significant difference for multiple comparisons of means.

The dynamic oscillatory frequency sweep test and the viscosity of DX and DS solutions were done in duplicate. The values shown are the average of the 2 measurements. 

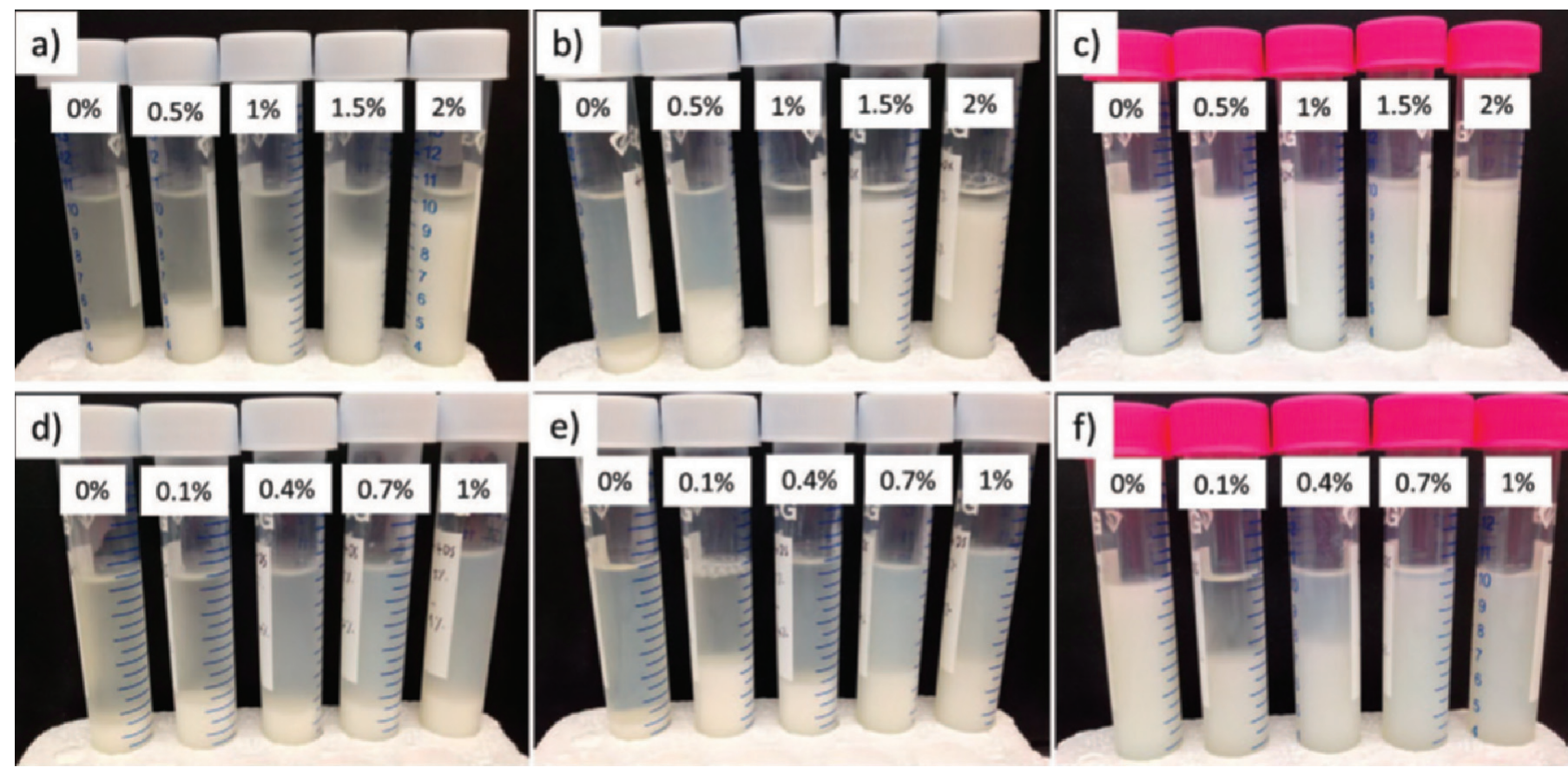

e)
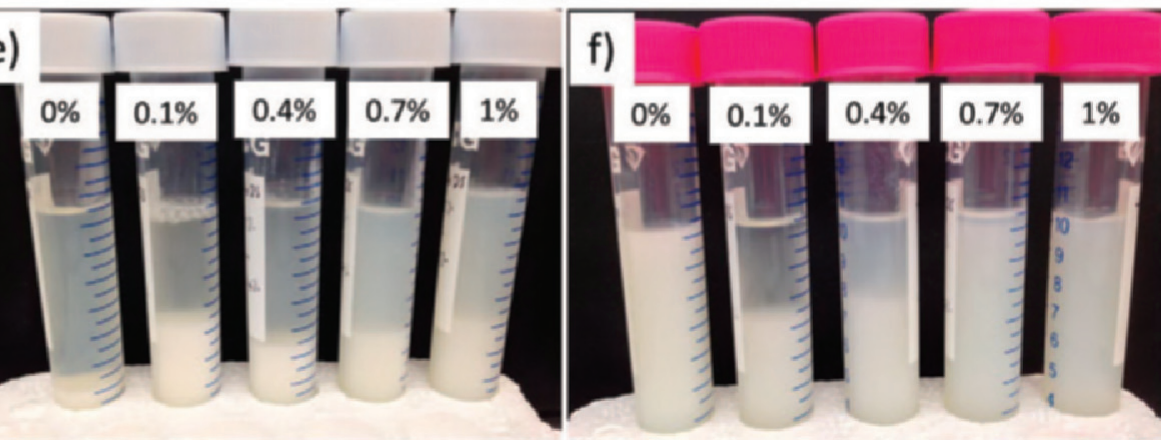

Figure 1. Phase separation of acidified milk proteins with dextran (DX; a, b, and c) or dextran sulfate (DS; d, e, and f) dispersions made with $5 \%$ milk solids after $24 \mathrm{~h}$ storage at approximately $0^{\circ} \mathrm{C}$. Concentrations of DX were between 0 and $2 \%$; concentrations of DS were between 0 and $1 \%$. Dispersions were made at $\mathrm{pH} 4.4$ ( $\mathrm{a}$ and $\mathrm{d}$ ), $\mathrm{pH} 4.6$ (b and $\mathrm{e}$ ), and $\mathrm{pH} 4.9$ (c and f). Color version available in the online PDF.

\section{RESULTS}

\section{Phase Separation}

Phase separation behavior of milk proteins $(5.0 \%$ milk solids) with DX or DS dispersions prepared at $\mathrm{pH} 4.4,4.6$, or 4.9 after $24 \mathrm{~h}$ storage at approximately $0^{\circ} \mathrm{C}$ is shown in Figure 1. Phase-separation results from samples made with higher milk solids content are not shown.

At $\mathrm{pH} 4.4$, for milk protein dispersions made with $5.0 \%$ milk solids, phase separation was readily found after $1 \mathrm{~h}$ in samples made with 0 to $1.5 \%$ DX (results not shown). After $24 \mathrm{~h}$, phase separation was observed for all samples, and the volume of the supernatant decreased as DX concentration increased (Figure 1a). At $7.5 \%$ milk solids content, phase separation was found only after $24 \mathrm{~h}$ in samples made with 0.5 to $2.0 \%$ DX (results not shown). In samples made with $\geq 10.0 \%$ milk solids, no phase separation was observed in control samples made without DX addition. However, supernatant was observed for some samples with high concentrations of DX (1.5 and 2.0\% DX). These samples were also very viscous.

At $\mathrm{pH}$ 4.6, samples made with $5.0 \%$ milk solids with 0 and $0.5 \%$ DX phase separated after $1 \mathrm{~h}$ (results not shown), but with higher DX concentrations, phase separation was observed only after $24 \mathrm{~h}$ of storage (Figure 1b). At $7.5 \%$ milk solids content, only samples made with 1.0 to $2.0 \%$ DX phase separated after $24 \mathrm{~h}$ (results not shown). At $\geq 10.0 \%$ milk solids content, supernatant was only observed from samples made with 1.5 and $2.0 \%$ DX.

At $\mathrm{pH} 4.8$ (results not shown) and 4.9 (Figure 1c), phase separation (small amounts) was only found after $24 \mathrm{~h}$ of storage for samples made with $5.0 \%$ milk solids with addition of 1.0 to $2.0 \%$ DX. At $7.5 \%$ milk solids content, phase separation was not observed in any samples (results not shown). At $\geq 10 \%$ milk solids, supernatant was observed from the samples made with 1.5 and $2.0 \%$ DX after $24 \mathrm{~h}$ of storage (results not shown).

For dispersions of milk proteins with DS at $5.0 \%$ milk solids at $\mathrm{pH}$ 4.4, phase separation was readily observed after $1 \mathrm{~h}$ for all samples (results not shown), and the volume of supernatant became larger after 24 h of storage (Figure 1d); the supernatants from samples made with 0.7 and $1.0 \%$ DS became turbid. At 7.5\% milk solids content, only samples made with addition of 0.7 to $1.0 \%$ DS, phase separated after $1 \mathrm{~h}$ (results not shown). At 10.0 to $12.5 \%$ milk solids content, phase separation was observed after $24 \mathrm{~h}$ for samples made with 0.4 to $1.0 \%$ DS (results not shown). Phase separation was not observed in samples made with $>12.5 \%$ milk solids content.

At $\mathrm{pH} 4.6$, phase separation was found in samples made with $5.0 \%$ milk solids with addition of 0 to $0.7 \%$ 
DS after $1 \mathrm{~h}$ (results not shown), but all samples phase separated after $24 \mathrm{~h}$ (Figure 1e). The supernatants from samples made with 0.7 and $1.0 \%$ DS became more turbid. At 7.5\% milk solids content, samples made with 0.4 to $1.0 \%$ DS showed phase separation after $24 \mathrm{~h}$ of storage (results not shown). At $10.0 \%$ milk solids, only samples made with $0.4 \%$ DS showed phase separation after $24 \mathrm{~h}$ of storage (results not shown). With $12.5 \%$ milk solids content, phase separation was observed only in samples made with addition of 0.4 and $0.7 \%$ DS. Phase separation was not observed in samples made with $>12.5 \%$ milk solids content.

At pH 4.8 (results not shown) and 4.9 (Figure 1f), the supernatant of the sample made with $5 \%$ milk solids with addition of $0.4 \%$ DS became more turbid than that from the sample made with $0.1 \%$ DS. Addition of 0.7 and $1.0 \%$ DS did not cause phase separation, but the samples changed from milky white to translucent. At $7.5 \%$ milk solids content with addition of $1.0 \%$ DS, the sample did not phase separate and the mixture became translucent (results not shown). Phase separation was not observed in samples made with higher milk solids content.

\section{Total Carbohydrate Analysis of the Supernatant}

Total carbohydrate results of the supernatant from acidified samples made with addition of DX are shown in Figure 2. Control samples without DX also contained carbohydrate due to the presence of lactose. As the concentration of DX increased, the total carbohydrate content of the supernatant significantly increased for all $\mathrm{pH}$ values. With an increase in milk solids content, the carbohydrate content increased as expected, due to more lactose.

Total carbohydrate concentration of supernatants from acidified dispersions of milk protein with added DS is shown in Figure 3. For all samples, no significant difference existed in the total carbohydrate content of samples made with the different concentrations of DS for $5.0 \%$ (as well as the $7.5 \%$ ) milk solids, except for the samples made with $7.5 \%$ milk solids at $\mathrm{pH}$ 4.6. The control sample $(7.5 \%$ milk solids at $\mathrm{pH} 4.6)$ had a significantly lower total carbohydrate content, but the total carbohydrate content of samples made with addition of $0.4,0.7$, and $1.0 \%$ DS were all similar to each other.

\section{Microstructure}

Fluorescence micrographs of dispersions of milk proteins at $\mathrm{pH} 4.6$ with added DX after $24 \mathrm{~h}$ of storage at approximately $0^{\circ} \mathrm{C}$ are shown in Figure 4. All samples made with $5 \%$ milk solids content had large clusters but cluster size decreased with increasing DX concentration (Figure 4a-e). Samples with high milk solids content (15\%) had much finer microstructure (Figure $4 \mathrm{f}-\mathrm{j}$ ) and, with increasing DX concentration, the microstructure became more granular or pore size increased.

Samples made with addition of DS after $24 \mathrm{~h}$ at $\mathrm{pH} 4.6$ are shown in Figure 5. All samples made with $5.0 \%$ milk solids (Figure 5a-e) had large clusters, and the size of clusters became larger with increasing DS concentration from 0 to $0.4 \%$ (Figure 5c), and then the clusters became more diffuse as we increased DS concentration to 0.7 and $1.0 \%$ (Figure $5 \mathrm{~d}$ and e, respectively). With higher milk solids content $(15 \%)$, the micrographs showed finer microstructure, and with increasing DS concentration, the microstructure became more granular (Figure $5 \mathrm{f}-\mathrm{j}$ ).

Samples made with $5.0 \%$ milk solids with addition of DS after $24 \mathrm{~h}$ at $\mathrm{pH} 4.9$ are shown in Figure 6. The size of casein clusters became larger with increasing DS concentration from 0 to $0.4 \%$ (Figure 6c) and as the DS concentration increased to 0.7 and $1.0 \%$, the casein cluster was no longer observed (Figure $6 \mathrm{~d}-\mathrm{e}$ ).

\section{Effect of DX or DS on Gelation}

Phase angle values measured at $0.075 \mathrm{~Hz}$ from the frequency sweep test are shown in Tables 1 and 2 for samples made with DX and DS addition, respectively. At $5.0 \%$ milk solids, all samples made with $\mathrm{DX}$ at $\mathrm{pH}$ 4.4 and 4.6 had phase angle values $<45^{\circ}$, but samples made at $\mathrm{pH} 4.8$ and 4.9 had decreasing phase angle values as DX concentration increased. Phase angle values of all samples made with $\geq 10 \%$ milk solids generally decreased as DX concentrations increased. These samples gelled when DX concentrations were between 1.0 and $2.0 \%$ DX. Phase angle values of samples made with DS at $5.0 \%$ milk solids content were $>45^{\circ}$ when $1.0 \%$ DS was added, indicating that the weak gel network was disrupted by DS addition. For higher milk solids content $(10.0,15.0$, and $20.0 \%$ milk solids; results of $15.0 \%$ milk solids not shown), the phase angle of the samples decreased as DS concentration increased. With addition of 0.7 to $1.0 \%$ DS, samples had phase angle values $<45^{\circ}$ at all $\mathrm{pH}$ levels.

\section{Viscosity of DX and DS solutions}

The viscosity of DX and DS solutions is shown in Figure 7. The viscosity of both DX and DS solutions was independent of the shear rate (results not shown), but it increased with an increase in the concentration of DX or DS, as expected. Dextran sulfate solutions had higher viscosities at each concentration level compared with DX solutions. 

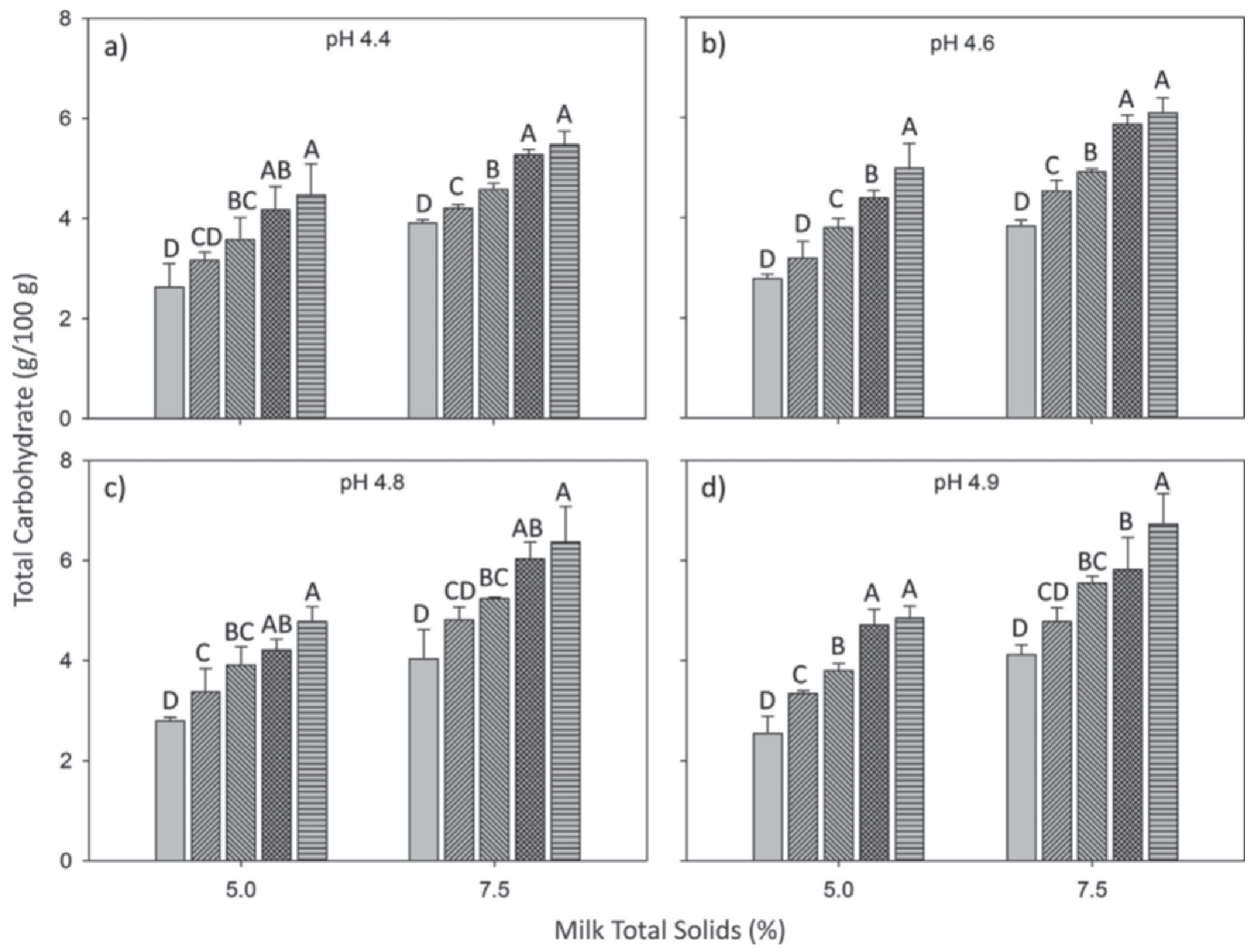

Figure 2. Total carbohydrate content of supernatants from dispersions of milk proteins with dextran (DX) at pH 4.4 (a), 4.6 (b), 4.8 (c), and 4.9 (d) with 5.0 and $7.5 \%$ milk solids content. Light gray bars $=0 \%$ DX; bars with diagonal stripes going up toward the right $=0.5 \%$ DX; bars with diagonal stripes going up toward the left $=1.0 \%$ DX; hatched bars $=1.5 \%$ DX; horizontally striped bars $=2.0 \%$ DX. Different capital letters $(\mathrm{A}-\mathrm{D})$ indicate significant differences for the same milk solids percentage within each $\mathrm{pH}$ group $(P<0.05)$.

\section{DISCUSSION}

This study investigated the effect of added uncharged DX or negatively charged DS to acidified milk samples at acidic $\mathrm{pH}$ values to better understand the possible interactions between milk proteins and polysaccharides in cultured products. To avoid the complications in the fermented milk (i.e., $\mathrm{pH}$ when EPS is produced is unknown and variation in concentration of EPS), we used a model of acidified milk to study the interactions and influences of polysaccharides on gel formation.

In general, incompatibility of proteins and polysaccharides is a common phenomenon, leading to spontaneous phase separation (Grinberg and Tolstoguzov, 1997). However, the system tends to be stable in dilute solutions as proteins and polysaccharides may be cosoluble (de Kruif and Tuinier, 2001). Cosolubility is a homogeneous solution, in which the 2 macromolecules do not interact (Goh et al., 2008). In this study, our acidified milk system at low milk solids content (5.0\%) without polysaccharide $(0 \%$ DX and DS) was unstable. After $24 \mathrm{~h}$ of storage at $0^{\circ} \mathrm{C}$, caseins aggregated and sedimented at the bottom of the tubes for samples made at $\mathrm{pH} 4.4$ and 4.6. The sedimentation of caseins might be explained as follows: casein micelles were destabilized during acidification; colloidal calcium phosphate was solubilized, net negative charges were reduced, and $\kappa$-CN hairs collapsed on the surface of casein particles (Lee and Lucey, 2010). These changes led to aggregation of caseins at a $\mathrm{pH}$ close to the isoelectric point of caseins at $\mathrm{pH} \leq 4.6$, although the rate and extent of aggregation were decreased by the use of 


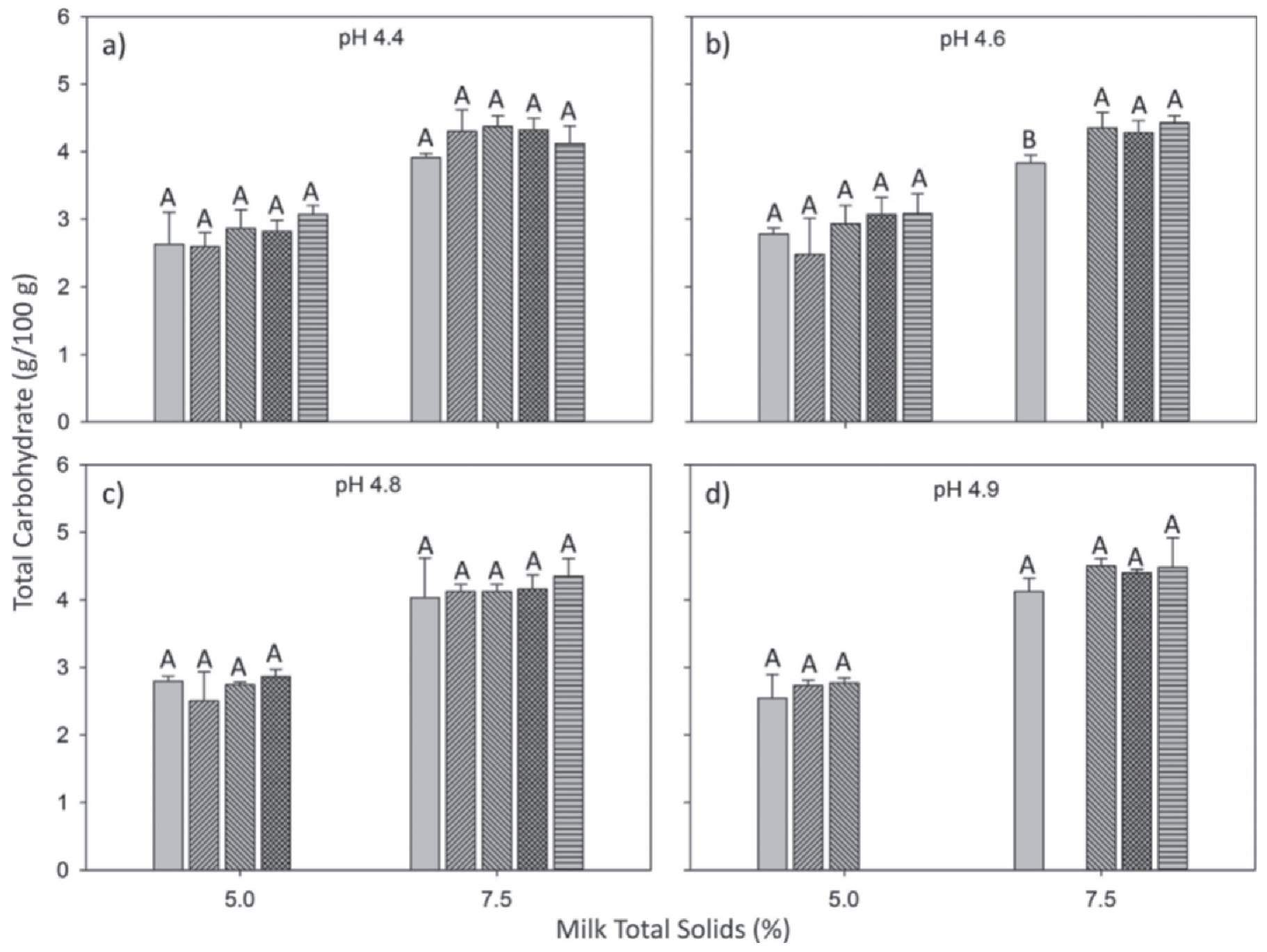

Figure 3. Total carbohydrate content of supernatants from dispersions of milk proteins with dextran sulfate (DS) at pH 4.4 (a), 4.6 (b), 4.8 (c), and 4.9 (d) with 5.0 and $7.5 \%$ milk solids content. Light gray bars $=0 \%$ DS; bars with diagonal stripes going up toward the right $=$ $0.1 \%$ DS; bars with diagonal stripes going up toward the left $=0.4 \%$ DS; hatched bars $=0.7 \%$ DS; horizontally striped bars $=1.0 \%$ DS. Some samples did not produce any supernatant, so no results were obtained for those samples. Different capital letters (A and B) indicate significant differences for the same milk solids percentage within each $\mathrm{pH}$ group $(P<0.05)$.

very low temperatures $\left(\sim 0^{\circ} \mathrm{C}\right)$. Micrographs (Figure $\left.4 \mathrm{a}\right)$ showed that after storage, caseins had aggregated and formed large clusters at $\mathrm{pH}$ 4.6. These large clusters were prone to sedimentation as explained by Stokes' law, in which the settling velocity is proportional to the square of particle diameter (Singh and Heldman, 2014). However, from the rheological analysis, these samples apparently formed weak gels (samples had phase angle $<45^{\circ}$ ) but the $\mathrm{G}^{\prime}$ values were only approximately 0.4 $\mathrm{Pa}$ after storage for $24 \mathrm{~h}$ (results not shown). It is more likely that we had sedimentation of unstable caseins at the bottom of the rheometer measuring cup, and the formation of this protein sediment contributed to the observed reduction in the phase angle.
For the samples made with DX from 0.5 to $2.0 \%$ at $\mathrm{pH} 4.4$ (Figure 1a), the volume of the supernatant decreased as DX concentration increased, probably because of the increased viscosity of the continuous phase with the addition of more DX (Figure 7). Stokes' law indicates that the settling velocity of particles is inversely proportional to the viscosity of the solution (Singh and Heldman, 2014). Therefore, the rate of the sedimentation of caseins decreased (and volume of the supernatant also decreased) with increasing DX concentration.

Upon increasing milk solids content $(>5.0 \%)$, gelation of the dispersions was observed when either 1.0 or $2.0 \%$ DX was added to samples (Table 1). For example, 

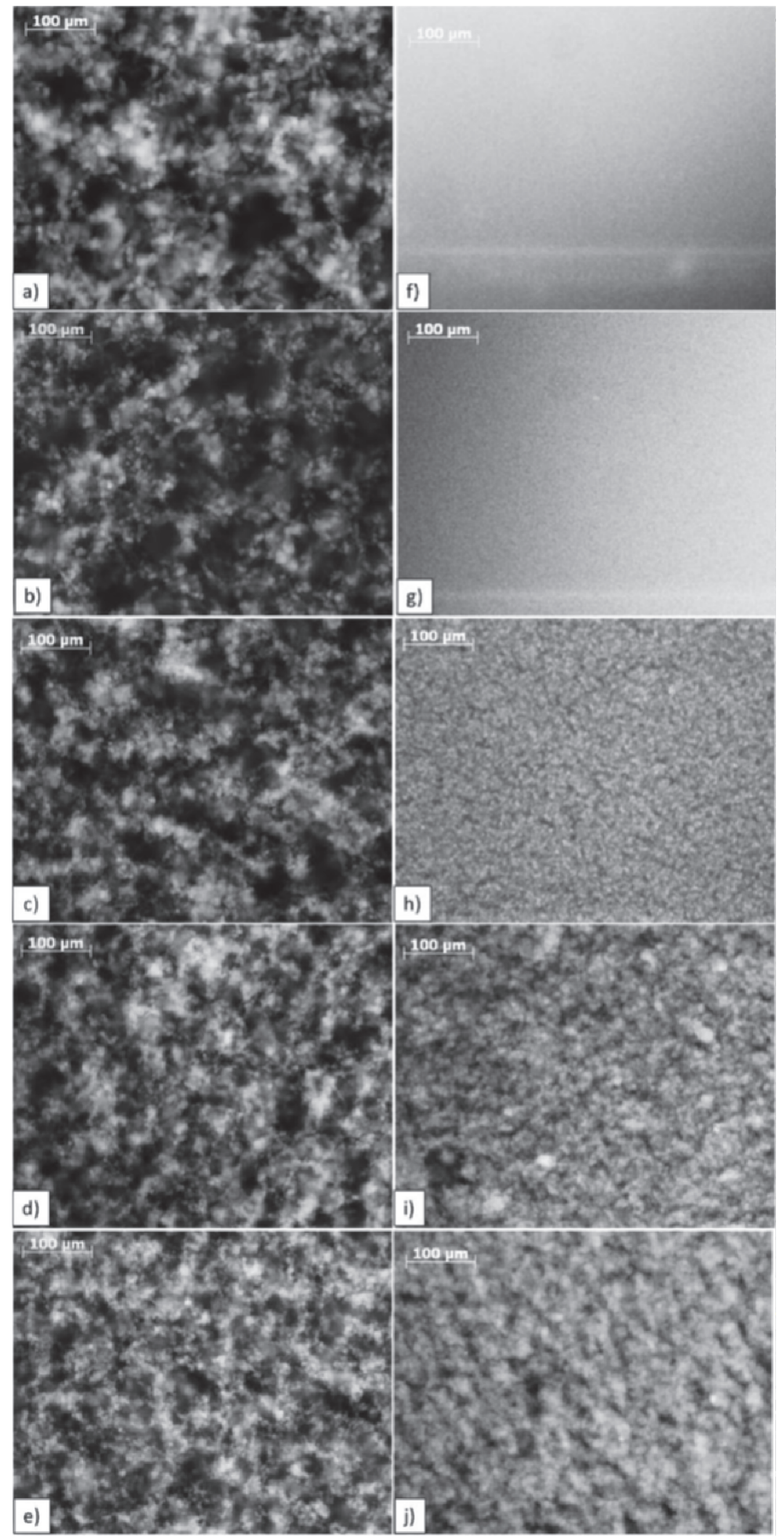

Figure 4. Micrographs of acidified ( $\mathrm{pH} 4.6)$ dispersions of milk proteins with dextran (DX) after $24 \mathrm{~h}$ of storage at approximately $0^{\circ} \mathrm{C}$ for samples made with $5 \%$ milk solids (a-e) and $15 \%$ milk solids $(\mathrm{f}-\mathrm{j})$. (a) and (f) were made without DX, (b) and (g) contained $0.5 \%$ DX, (c) and (h) contained $1.0 \% \mathrm{DX},(\mathrm{d})$ and (i) contained $1.5 \% \mathrm{DX}$, and $(\mathrm{e})$ and $(\mathrm{j})$ contained $2.0 \% \mathrm{DX}$. 

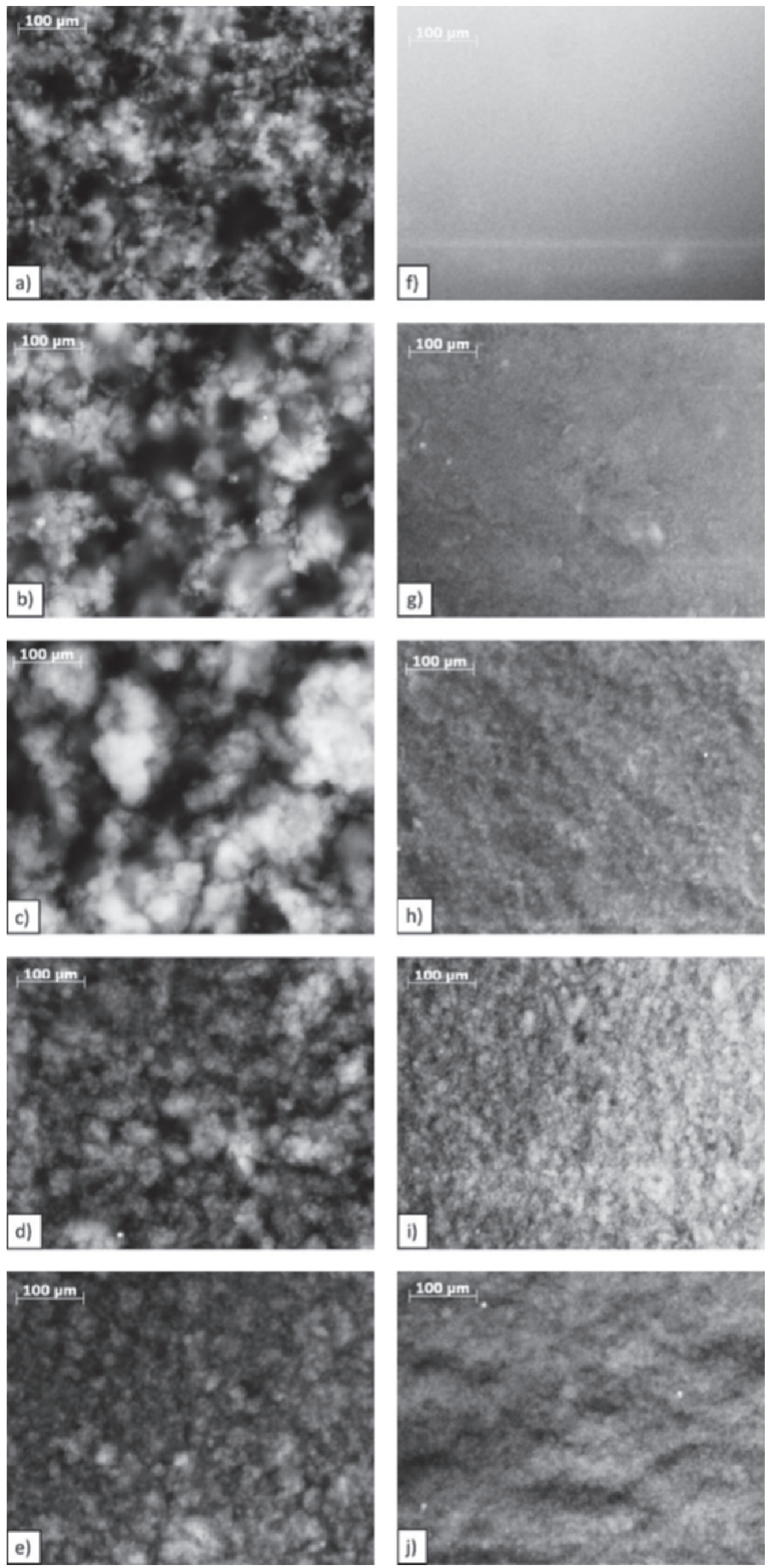

Figure 5. Micrographs of acidified ( $\mathrm{pH} 4.6)$ dispersions of milk proteins with dextran sulfate (DS) after 24 h storage at approximately $0^{\circ} \mathrm{C}$ for samples made with $5 \%$ milk solids (a-e) and $15 \%$ milk solids $(\mathrm{f}-\mathrm{j})$. (a) and (f) were made without DS, (b) and (g) contained $0.1 \%$ DS, (c) and (h) contained 0.4\% DS, (d) and (i) contained 0.7\% DS, and (e) and (j) contained 1.0\% DS. 

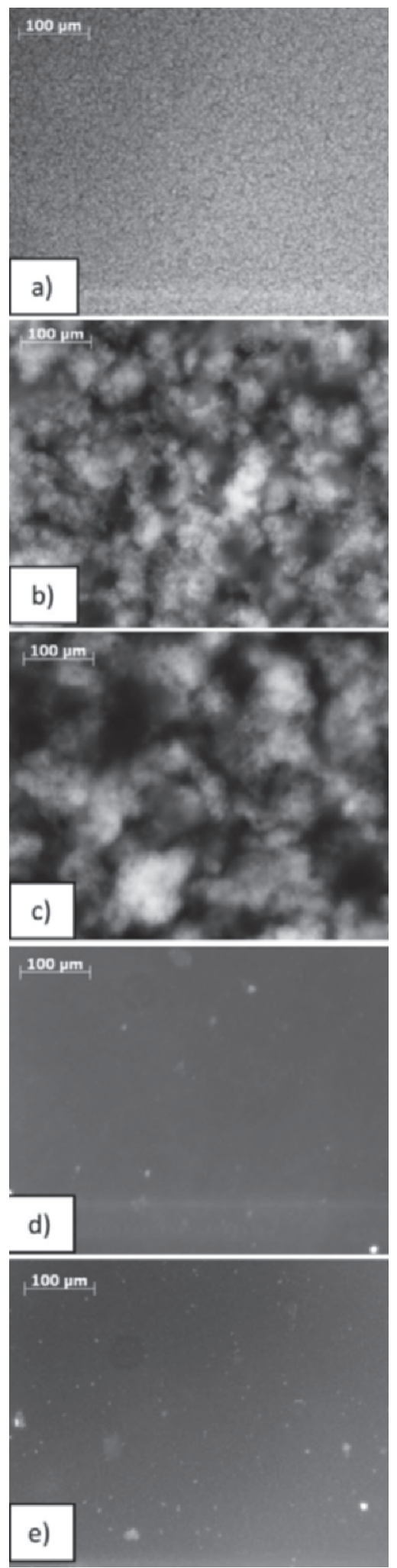

Figure 6. Micrographs of acidified ( $\mathrm{pH} 4.9$ ) dispersions of milk proteins with dextran sulfate (DS) after $24 \mathrm{~h}$ of storage at approximately $0^{\circ} \mathrm{C}$ for samples made with $5 \%$ milk solids. (a) was made without DS, (b) contained $0.1 \%$ DS, (c) contained $0.4 \%$ DS, (d) contained $0.7 \%$ DS, and (e) contained $1.0 \%$ DS. the sample made with $10.0 \%$ milk solids, at $\mathrm{pH} 4.4$ and with the addition of $2.0 \%$ DX, had a phase angle of $13^{\circ}$ and $\mathrm{G}^{\prime}$ values of approximately $9 \mathrm{~Pa}$ (results not shown) after storage for $24 \mathrm{~h}$. Addition of a high concentration of DX to milk protein dispersions could result in increased attraction between protein particles (de Kruif and Tuinier, 2001); hence, gelation of the samples occurred. Other nonadsorbing polysaccharides (i.e., guar gum) were also reported to increase attraction between casein particles (Everett and McLeod, 2005). This attraction mechanism is called depletion flocculation; this occurs when noninteracting polysaccharides are added to a protein solution and the osmotic pressure gradient of the polysaccharide molecules surrounding the protein particles causes an additional attractive force between the particles (Goh et al., 2008). This mechanism was confirmed by total carbohydrate analysis. For samples with the same milk solids content, if the total carbohydrate in supernatant was constant as the added DX concentration was increased from 0 to $2.0 \%$ (or as the DS concentration was increased from 0 to $1.0 \%$ ), we assumed that phase separation resulted from associative interaction, in which the caseins and polysaccharides formed complexes and aggregated; thus, the carbohydrate content in the supernatant would not increase with increasing levels of DX or DS. On the other hand, if total carbohydrate content in the supernatant increased as DX or DS concentrations were increased, this would indicate phase separation, due to depletion flocculation.

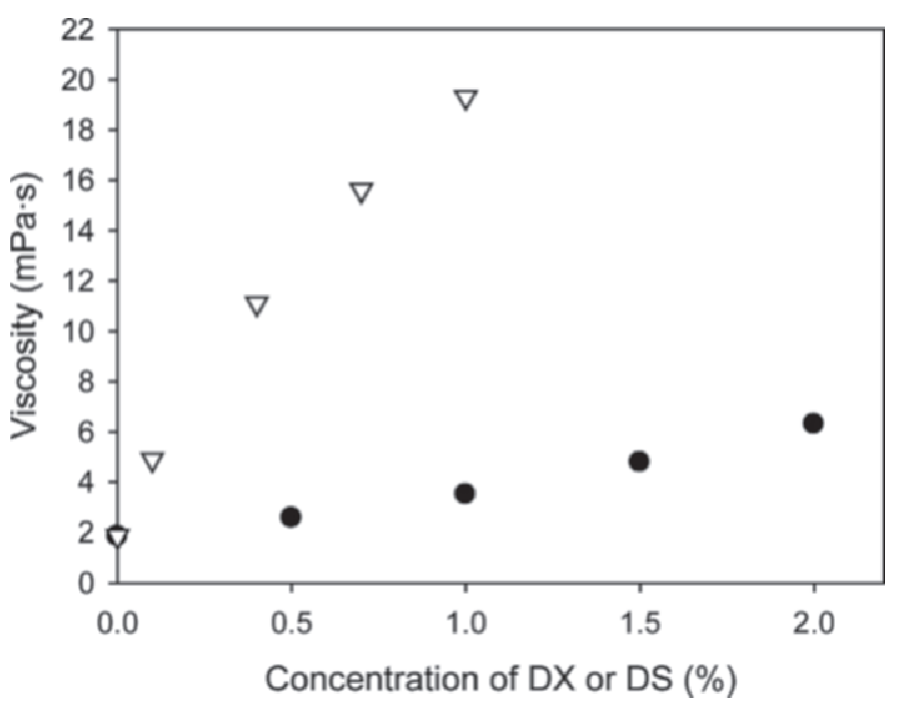

Figure 7. Viscosity of dextran (DX; $\bullet$ ) and dextran sulfate (DS; $\nabla)$ solutions at various concentrations at approximately $0^{\circ} \mathrm{C}$, measured at a shear rate of $351 \mathrm{~s}^{-1}$. The concentration of $0 \%$ DX or DS was measured from deionized water at $0^{\circ} \mathrm{C}$. Viscosity was an average of 2 measurements. 
Table 1. Effect of addition of dextran (DX) on the phase angle $\left(^{\circ}\right)$ from dynamic oscillatory rheology test of acidified milk protein dispersions at approximately $0^{\circ} \mathrm{C}$ and a $\mathrm{pH}$ range of 4.4 to $4.9^{1}$

\begin{tabular}{|c|c|c|c|c|c|c|c|c|c|c|c|c|}
\hline \multirow[b]{2}{*}{ DX (\%) } & \multicolumn{4}{|c|}{$5 \%$ milk solids } & \multicolumn{4}{|c|}{$10 \%$ milk solids } & \multicolumn{4}{|c|}{$20 \%$ milk solids } \\
\hline & 4.4 & 4.6 & 4.8 & 4.9 & 4.4 & 4.6 & 4.8 & 4.9 & 4.4 & 4.6 & 4.8 & 4.9 \\
\hline 0 & $11^{2}$ & $29^{2}$ & 64 & 67 & 65 & 90 & 73 & 90 & 90 & 90 & 90 & 75 \\
\hline 1.0 & $21^{2}$ & $23^{2}$ & $41^{2}$ & 66 & $12^{2}$ & $29^{2}$ & 52 & 90 & 67 & 53 & 50 & 63 \\
\hline 2.0 & $21^{2}$ & $30^{2}$ & $29^{2}$ & $33^{2}$ & $13^{2}$ & $16^{2}$ & $19^{2}$ & $25^{2}$ & $14^{2}$ & $10^{2}$ & $24^{2}$ & $24^{2}$ \\
\hline
\end{tabular}

${ }^{1}$ Samples with a phase angle $<45^{\circ}$ were considered gels.

${ }^{2}$ Samples with phase angle $<45^{\circ}$.

The total carbohydrate content of the supernatants from milk protein dispersions made with DX (at the same milk solids content) significantly increased as DX concentration increased (Figure 2). This indicates that the increase in carbohydrate content of the supernatant was caused by the increasing DX concentration that was added to the sample. Therefore, we assume that caseins and DX did not associatively interact, and that DX addition could have induced a depletion flocculation-type mechanism, which resulted in aggregation and protein network formation in these samples.

Dextran sulfate molecules carry negative charges (1.9 sulfate groups/glucosyl residue), which were fully ionized across the $\mathrm{pH}$ range in this study (4.4-4.8), which could be adsorbed onto caseins at locations where positive local patches are present (which depends on the $\mathrm{pH}$ of the system). At $5.0 \%$ milk solids and with a low concentration of DS (0.1 and $0.4 \%)$, phase separation was still observed (Figure 1d, e, and f), but as DS concentration was increased to $1.0 \%$, a stabilization effect of DS on milk protein dispersions was observed, especially at $\mathrm{pH} 4.9$ (Figure 1f), where no phase separation was observed. At low concentration of DS, the amount of DS was probably not sufficient to fully cover all the caseins, so a DS molecule might be adsorbed to more than 1 casein surface, which could result in bridging between caseins and polysaccharides, leading to sedimentation or phase separation (de Kruif and Tuinier, 2001). An increase in DS concentration $(>0.4 \%)$ resulted in more stable systems (at $5.0 \%$ milk solids) where the larger quantity of DS might be sufficient to cover all caseins and inhibit sedimentation due to the increased charge repulsion of DS-casein particles. Micrographs helped reveal the type of interactions between caseins and DS. Sample made with $5.0 \%$ milk solids and $0.4 \%$ DS (Figures 5c and 6c) had very large aggregates, which could result from bridging between casein-DS and casein-casein particles. When the DS concentration increased to $1.0 \%$ (Figures 5e and 6e), the casein clusters became much smaller and system structure finer as caseins were possibly fully covered by DS, causing repulsion and thereby stabilization, especially at $\mathrm{pH} 4.9$, where the casein cluster was not observed (Figure 6e). Rheological analyses also showed that the samples at $5.0 \%$ milk solids content with $1.0 \% \mathrm{DS}$ (at all pH levels) had phase angles $>45^{\circ}$ ( $\mathrm{G}^{\prime}$ values $<0.1 \mathrm{~Pa}$; results not shown), indicating that these samples did not gel (Table 2). This result was in agreement with Maroziene and de Kruif (2000), who found that when the pectin (also a negatively charged biopolymer) concentration was too low to have full coverage of caseins (at $\mathrm{pH} 5.3$ ), interconnection or bridging of pectin between caseins occurred. On increasing the pectin content, the system became (repulsively) stabilized when pectins fully coated the casein particles (Maroziene and de Kruif, 2000; Everett and McLeod, 2005). The supernatants of samples with high DS levels were turbid (Figure 1d, e, and $\mathrm{f}$ ) because DS associatively interacted with caseins

Table 2. Effect of addition of dextran sulfate (DS) on the phase angle from dynamic oscillatory rheology test of acidified milk protein dispersions at approximately $0^{\circ} \mathrm{C}$ and a $\mathrm{pH}$ range of 4.4 to $4.9^{1}$

\begin{tabular}{|c|c|c|c|c|c|c|c|c|c|c|c|c|}
\hline DS (\%) & \multicolumn{4}{|c|}{$5 \%$ milk solids } & \multicolumn{4}{|c|}{$10 \%$ milk solids } & \multicolumn{4}{|c|}{$20 \%$ milk solids } \\
\hline 0 & $11^{2}$ & $29^{2}$ & 64 & 67 & 65 & 90 & 73 & 90 & 90 & 90 & 90 & 75 \\
\hline 0.4 & $25^{2}$ & $22^{2}$ & $17^{2}$ & $20^{2}$ & $31^{2}$ & $19^{2}$ & $15^{2}$ & $15^{2}$ & 65 & $23^{2}$ & $16^{2}$ & $15^{2}$ \\
\hline 0.7 & 71 & $38^{2}$ & $40^{2}$ & 45 & $18^{2}$ & $17^{2}$ & $15^{2}$ & $14^{2}$ & $20^{2}$ & $14^{2}$ & $14^{2}$ & $12^{2}$ \\
\hline 1.0 & 71 & 59 & 51 & 60 & $18^{2}$ & $16^{2}$ & $15^{2}$ & $16^{2}$ & $17^{2}$ & $17^{2}$ & $13^{2}$ & $12^{2}$ \\
\hline
\end{tabular}

${ }^{1}$ Samples with a phase angle $<45^{\circ}$ were considered gels.

${ }^{2}$ Samples with phase angle $<45^{\circ}$. 
and prevented them from forming large clusters and sedimenting. The stabilization effect of DS was confirmed by the micrographs at $\mathrm{pH} 4.9$ (Figure 6d-e), in which the casein cluster was not observed when 0.7 or $1.0 \%$ DS was added to the samples.

High protein concentrations $(\geq 10 \%$ milk TS) and high DS concentrations $(>0.4 \%)$ caused gelation of samples (Table 2). The $\mathrm{G}^{\prime}$ values of these gels were high and ranged from 3 to $103 \mathrm{~Pa}$ (results not shown). As DS molecules carried negative charges, they could associatively interact with positively charged local patches on casein particles at low $\mathrm{pH}$ values (Dickinson, 1998). The volume fraction of aggregates/complexes in the system might have been sufficient for gelation. An electrostatic associative interaction between caseins and polysaccharides was confirmed by carbohydrate analysis, in which we found no significant increase in total carbohydrate content of the supernatants from samples (at the same milk solids content) as the DS concentration increased (Figure 3). This indicates that caseins and DS molecules associatively interacted and formed protein-polysaccharide complexes. A similar type of gelation mechanism was reported by Girard and Schaffer-Lequart (2008) for milk samples during acidification with negatively charged biopolymers. The microstructures of gelled samples made with high milk protein content (15\%) and the addition of 0.7 or $1.0 \%$ DS (Figure 5i and $\mathrm{j}$ ) showed a finely distributed network. This is in agreement with Sanchez et al. (2000), who found fibrous-like structures using scanning electron microscopy from samples made from skim milk and negatively charged xanthan gum mixtures.

\section{CONCLUSIONS}

This study helps to understand the various types of interaction mechanisms that can occur between caseins and polysaccharides in acidic conditions. Uncharged DX interacted with caseins through depletion flocculation, which could result in the gelation of systems made with high concentrations of DX. Negatively charged polysaccharides (DS) interacted with caseins through associative electrostatic interactions. At low milk solids content (i.e., low protein levels), a high concentration of DS could repulsively stabilize the system from sedimentation, whereas at high milk concentrations, DS could form complexes with caseins that then aggregated to form gels.

\section{ACKNOWLEDGMENTS}

This material is based upon work supported by the National Institute of Food and Agriculture, United
States Department of Agriculture (Washington, DC), under project WIS01650 (Hatch).

\section{REFERENCES}

Bradley, R. L., E. Arnold, D. M. Barbano, R. G. Semerad, D. E. Smith, and B. K. Vines. 1992. Chemical and physical methods. Pages 433-531 in Standard Methods for the Examination of Dairy Products. R. T. Marshall, ed. 16th ed. American Public Health Association, Washington, DC.

Corredig, M., N. Sharafbafi, and E. Kristo. 2011. Polysaccharide-protein interactions in dairy matrices, control and design of structures. Food Hydrocoll. 25:1833-1841.

de Kruif, C. G., and R. Tuinier. 2001. Polysaccharide protein interactions. Food Hydrocoll. 15:555-563.

Dickinson, E. 1998. Stability and rheological implications of electrostatic milk protein-polysaccharide interactions. Trends Food Sci Technol. 9:347-354

Doublier, J.-L., C. Garnier, D. Renard, and C. Sanchez. 2000. Proteinpolysaccharide interactions. Curr. Opin. Colloid Interface Sci. 5:202-214

DuBois, M., K. A. Gilles, J. K. Hamilton, P. A. Rebers, and F. Smith 1956. Colorimetric method for determination of sugars and related substances. Anal. Chem. 28:350-356.

Everett, D. W., and R. E. McLeod. 2005. Interactions of polysaccharide stabilisers with casein aggregates in stirred skim-milk yoghurt. Int. Dairy J. 15:1175-1183.

Girard, M., and C. Schaffer-Lequart. 2008. Attractive interactions between selected anionic exopolysaccharides and milk proteins. Food Hydrocoll. 22:1425-1434.

Goh, K., A. Sarkar, and H. Singh. 2008. Milk protein-polysaccharide interactions. Pages 347-376 in Milk Proteins: From Expression to Food. A. Thompson, M. Boland, and H. Singh, ed. Academic Press, New York, NY.

Grinberg, V. Y., and V. B. Tolstoguzov. 1997. Thermodynamic incompatibility of proteins and polysaccharides in solutions. Food Hydrocoll. 11:145-158.

Lee, W. J., and J. A. Lucey. 2010. Formation and physical properties of yogurt. Asian-australas. J. Anim. Sci. 23:1127-1136.

Maroziene, A., and C. G. de Kruif. 2000. Interaction of pectin and casein micelles. Food Hydrocoll. 14:391-394.

McClements, D. J. 2000. Comments on viscosity enhancement and depletion flocculation by polysaccharides. Food Hydrocoll. 14:173177.

Roefs, S. P. F. M. 1986. Structure of acid casein gels: A study of gels formed after acidification in the cold. $\mathrm{PhD}$ Thesis. Wageningen Agricultural University, Wageningen, the Netherlands.

Ruas-Madiedo, P., R. Tuinier, M. Kanning, and P. Zoon. 2002. Role of exopolysaccharides produced by Lactococcus lactis ssp. cremoris on the viscosity of fermented milks. Int. Dairy J. 12:689-695.

Sanchez, C., R. Zuniga-Lopez, C. Schmitt, S. Despond, and J. Hardy. 2000. Microstructure of acid-induced skim milk-locust bean gumxanthan gels. Int. Dairy J. 10:199-212.

Singh, R. P., and D. R. Heldman. 2014. Supplemental processes. Pages 711-742 in Introduction to Food Engineering. 5th ed. R. P. Singh and D. R. Heldman, ed. Academic Press, San Diego, CA

Tolstoguzov, V. B. 1991. Functional properties of food proteins and role of protein-polysaccharide interaction. Food Hydrocoll. 4:429468.

Tuinier, R., J. Rieger, and C. G. de Kruif. 2003. Depletion-induced phase separation in colloid polymer mixtures. Adv. Colloid Interface Sci. 103:1-31. 